\title{
Expression of Tau Protein and Tau mRNA in gastric carcinoma
}

\author{
Chun-hui Li' ${ }^{1}$, Li-Hui Pan², Rajina Sahi ${ }^{3}$, Zhao Xing ${ }^{1}$, Cheng Yu' ${ }^{2}$, Zhang De-Li ${ }^{1}$ \\ ${ }^{1}$ Affiliated Hospital of Chengde Medical College, Chengde 067000, Hebei Province, China, ${ }^{2}$ Chengde Medical College, Chengde 067000, \\ Hebei Province, China, ${ }^{3}$ B.P. Koirala Memorial Cancer Hospital
}

\section{A B S T R A C T}

Aims and Objectives: To provide theoretical basis for the gastric carcinoma pathogenesis and the clinical targeted therapy. Materials and Methods: We detected the expression of Tau protein and Tau mRNA in 60 cases of gastric carcinoma tissues (observation group) and 10 cases of normal gastric tissues (control group). Immunohistochemisty was adopted to detect the expression of Tau protein in normal and carcinomatous gastric tissue. Tau mRNA was detected by RT-PCR in normal and carcinomatous gastric tissue. To analyse the experimental data combined clinical pathology with statistics. Results: The expression of Tau protein in carcinomatous gastric tissue was higher than that in normal gastric tissue $(P<0.05)$. The expression of Tau protein and Tau mRNA in well differentiated and moderately differentiated was lower than that in poorly differentiated gastric carcinoma $(P<0.05)$. The expression of Tau protein and Tau mRNA in gastric carcinoma without lymph node metastasis was lower than that in gastric carcinoma with lymph node metastasis $(P<0.05)$. The expression of Tau mRNA in carcinomatous gastric tissue was higher than that in normal gastric tissue $(P<0.05)$. Conclusion: Tau protein and Tau mRNA were significant differences between normal gastric tissue and gastric carcinoma, also were concerned with differentiation in grade and lymph node metastasis of gastric carcinoma.

Key words: Gastric carcinoma, Tau protein, mRNA, Reverse transcription polymerase chain reaction, Immunohistochemistry

\section{INTRODUCTION}

Microtubule associated protein (MAP) is non-microtubule structure protein and combine with microtubule. At present, the MAP which have been found and purified mainly include MAP-1, MAP-2, MAP-4 and Tau protein. ${ }^{1,2}$ They participate in the assembling of microtubule, maintaining the stability of microtubule, connecting microtubule with other skeleton fibers, and playing a wide range of functional role. Tau protein is the combination of microtubule polymerization protein and microtubules, and can induce microtubules fasciculation, and reinforce the stability of microtubules. ${ }^{3,4}$ Microtubules are the main components of spindles in mitotic phase, which can make the cell cycle proceed smoothly, providing conditions for the infinite proliferation of cancer cells. Tau protein just assists in such function of microtubules. Tau protein may accelerate the progress of malignant tumors. This research aims to discuss the effect of Tau protein and Tau mRNA on the occurrence and development of the gastric carcinoma.

\section{MATERIALS AND METHODS}

Clinical data were collected from the period of December 2008 to March 2010 compromising of 60 cases of gastric carcinoma tissues, confirmed by pathological diagnosis (observation group) and 10 cases of normal gastric tissue (control group) from the Affiliated Hospital of Chengde Medical College. Among these 60 cases, 49 cases were males and 11 cases were females. Their age ranged from 43 to 77 , and the average age was $58.3 \pm 10.0$. Twenty-eight cases 
were of well differentiated gastric carcinoma and 32 cases were poorly differentiated gastric carcinoma. Twenty-five cases were without lymph node metastasis and 35 cases were with lymph node metastasis.

\section{Reverse transcription--PCR}

Reagents AMV first chain cDNA synthesis kit was bought from Shanghai Sheng Gong biological engineering technology service company.

Primers was synthesized by Shanghai Sheng Gong biological engineering technology service company.

$\beta$-actin upstream primer (5'to 3'):CAT GTA CGT TGC TAT CCA GGC

$\beta$ —actin downstream primer (5'to 3'):CTC CTT AAT GTC ACG CAC GAT

Tau upstream primer (5'to 3'): GTG ACC CAA GAG CCT GAA AGT

Tau downstream primer (5'to 3'): GGT GCA GGT CTC CTA GAA GC

50bp DNA Ladder was bought from Beijing Tiangen biochemical, LTD (MD108).

TRIZOL was bought from Invitrogen company; ethidium bromide was bought from the Promeda compony of America. Conventional reagents, such as chloroform, isopropanol, absolute alcohol, EDTA,Tris-acetic acid, Tris-boric acid, $\mathrm{NaOH}, \mathrm{DEPC}$, Agarose were bought from Beijing chemical reagent company.

We added $1 \mathrm{ml}$ Trizol extract to $50-100 \mathrm{mg}$ tissue samples, and fully homogenated at room temperature, then centrifuged, extracted RNA samples from supernatant and synthesized cDNA as the kit instruction. The amplification condition of PCR: $95^{\circ} \mathrm{C}$ pre-degenerated $5 \mathrm{~min} ; 95^{\circ} \mathrm{C}$ degenerated $45 \mathrm{~s}$, $69^{\circ} \mathrm{C}$ annealed $45 \mathrm{~s}, 72^{\circ} \mathrm{Cextended} 30$ s, circulated 40 times; $72^{\circ} \mathrm{C}$ ended reaction by final extending $10 \mathrm{~min}$. The products were placed at $4^{\circ} \mathrm{C}$ for electrophoresis detection or at $-20^{\circ} \mathrm{C}$ for long-term preservation. Ten $\mu \mathrm{l} \mathrm{PCR}$ product was analysed by $1.5 \%$ agarose gel electrophoresis, and after EB dyeing, it was taken pictures by the UV fluorescence digital formatter and analysed optical density quantitatively. The ratio of cumulative optical density of the Tau protein and the corresponding $\beta$-actin augmentation product strap was looked as the relative expression quantity of Tau protein.

\section{Immunohistochemistry method}

Tissue samples was fixed by $10 \%$ formalin and then embeded by paraffins. Four $\mu \mathrm{m}$ serial sectioned were taken, repairing antigen with microwave, and immunohistochemistry stained. We found that the positive signal of Tau protein expressed in cytoplasm of normal gastric tissue and gastric carcinoma tissues. We selected 5 high power lens field of vision $(\times 400)$ in the dyeing uniform regions: (1) Grading by positive cells percentage: $<25 \%$ as 1 point, $25 \%-5 \%$ as 2 points, $>25 \%$ as 3 points; (2) Grading by dyeing intensity: no staining as 0 point, light buffy as 1 point, clay bank as 2 points, brown as 3 points. By synthesizing the count of dyeing positive cell(A)and dyeing intensity, the results came out: negative (-):0 point, weak positive $(+): 1-2$ points, moderately positive $(++): 3-4$ points, strongly positive $(+++)$ : 5-6 points.

\section{Statistical analysis}

The statistical treatment of the experimental data was completed with statistical softwave SPSS11.5, the measurement data were expressed as mean \pm standard deviation, and was detected by the two Independent samples $\mathrm{t}$ text and $p<0.05$ was regarded as indicating a significant differentce.

\section{RESULTS}

\section{RT-PCR Results}

The relative amount:10 cases of normal gastric tissue was $0.53 \pm 0.01 ; 60$ cases of carcinomatous gastric tissue was $0.78 \pm 0.08$. The well and moderately differentiated gastric carcinoma were $0.70 \pm 0.03$; The poorly differentiated was $0.86 \pm 0.02$. The cases without lymph node metastasis was $0.74 \pm 0.07$; The cases with lymph node metastasis was $0.81 \pm 0.08$. The data was texted by the two Independent Sample Text.We found that the expression of Tau mRNA in normal gastric tissue was inferior to that in carcinomatous gastric tissue, the expression of Tau mRNA in well and moderately differentiated carcinomatous gastric tissue was inferior to that in poorly differentiated carcinomatous gastric tissue, the expression of Tau mRNA in carcinomatous gastric tissue without lymph node metastasis was inferior to that in carcinomatous gastric tissue with lymph node metastasis. $\mathrm{P}<0.05$ was regarded as indicating a significant different (Figure 1(a,b,c), Table 1).

\begin{tabular}{lccc}
\multicolumn{4}{l}{ Table 1: The expression of Tau mRNA in normal } \\
and carcinomatous gastric tissue $(\bar{\chi} \pm \mathbf{S})$ \\
\hline Group & $\mathbf{N}$ & IOD & $\mathbf{P}$ \\
\hline Normal & 10 & $0.53 \pm 0.01$ & $P<0.05$ \\
$\begin{array}{l}\text { Gastric carcinoma } \\
\text { Differentiation }\end{array}$ & 60 & $0.78 \pm 0.08$ & \\
$\quad$ Well and moderately & 28 & $0.70 \pm 0.03$ & $P<0.05$ \\
$\quad$ Poorly & 32 & $0.86 \pm 0.02$ & \\
Lymph node metastasis & & & \\
- & 25 & $0.74 \pm 0.07$ & $P<0.05$ \\
+ & 35 & $0.81 \pm 0.08$ & \\
\hline
\end{tabular}




\section{Immunohistochemistry results}

The expression results of Tau protein in 10 cases of normal gastric tissue were as follows: 3 cases were negative, 6 cases were weakly positive, 1 case was moderately positive, and none was strongly positive. The expression results of Tau protein in 60 cases of carcinomatous gastric tissue were as follows: 10 cases were negative, 10 cases were weakly positive, 16 cases were moderately positive, 24 cases were strongly positive. Twenty-eight cases were well differentiated, 32 cases were poorly differentiated, 25 cases were without lymph node metastasis and 35 cases had lymph node metastasis. The expression results of Tau protein of the well and moderately differentiated was: 8 cases were negative, 6 cases were weakly positive, 10 cases were moderately positive, 4 cases were strongly positive. The expression results of Tau protein of the poorly differentiated was: 2 cases were negative, 4 cases were weakly positive, 6 cases were moderately positive, 20 cases were strongly positive; The expression results of Tau protein in the cases without lymph node metastasis was: 6 cases were negative, 5 cases were weakly positive, 12 cases were moderately positive, 2 cases were strongly positive; The expression results of Tau protein in the cases with lymph node metastasis was: 4 cases were negative, 5 cases were weakly positive, 4 cases were moderately positive, 22 cases were strongly positive. The data was handled by the Two Independent rank-sum test. We found that the expression of Tau protein in normal gastric

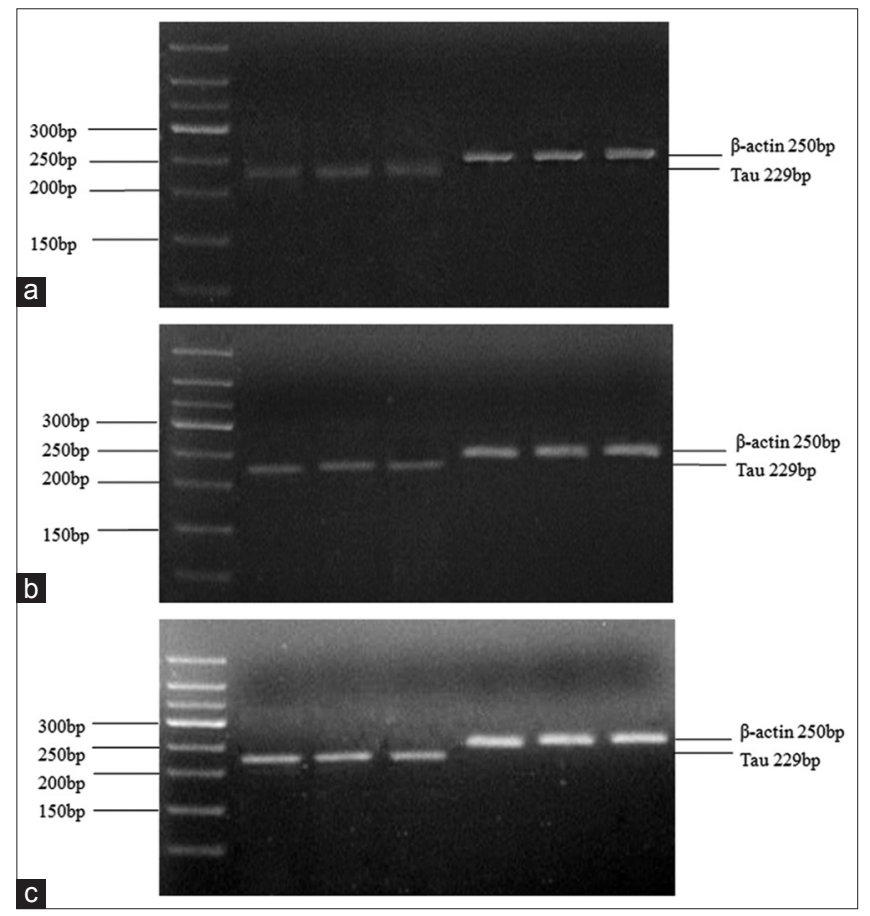

Figure 1: (a) Tau protein mRNA expression in normal gastric tissue. (b) Tau protein mRNA expression in Well-moderately differentiated gastric carcinoma. (c) Tau protein mRNA expression in poorly differentiated gastric carcinoma tissue was inferior to that in carcinomatous gastric tissue, the expression of Tau protein in well and moderately differentiated carcinomatous gastric tissue was inferior to that in poorly differentiated carcinomatous gastric tissue, the expression of Tau protein in carcinomatous gastric tissue without lymph node metastasis was inferior to that in carcinomatous gastric tissue with lymph node metastasis $(p<0.050)$ regarded as a significant difference Figure 2(a,b,c), Table 2.

\section{DISCUSSION}

Tau protein is one kind of phosphoprotein and it has little molecular mass. Tau protein is discovered predominantly in neuraxis and dendrite and the adjustment of its phosphorylation level is distinct along with up growths. Six isomerides which contain 352-441 amino acid residues can be found in brains of adult. Since the difference from existing and lacking three insertion elements, the carboxyl terminus of every Tau protein contains 3-4 repeated sequences, which consist of 31-32 amino acid residues.

\begin{tabular}{|c|c|c|c|c|c|c|}
\hline \multirow[t]{2}{*}{ Group } & \multirow[t]{2}{*}{$\mathbf{N}$} & \multicolumn{4}{|c|}{ Grade } & \multirow[t]{2}{*}{$\mathbf{P}$} \\
\hline & & - & + & ++ & +++ & \\
\hline Normal & 10 & 3 & 6 & 1 & 0 & $P<0.05$ \\
\hline Gastric carcinoma & 60 & 10 & 10 & 16 & 24 & \\
\hline \multicolumn{7}{|l|}{ Differentiation } \\
\hline Well and moderately & 28 & 8 & 6 & 10 & 4 & $P<0.05$ \\
\hline Poorly & 32 & 2 & 4 & 6 & 20 & \\
\hline \multicolumn{7}{|l|}{ Lymph node metastasis } \\
\hline - & 25 & 6 & 5 & 12 & 2 & $P<0.05$ \\
\hline+ & 35 & 4 & 5 & 4 & 22 & \\
\hline
\end{tabular}

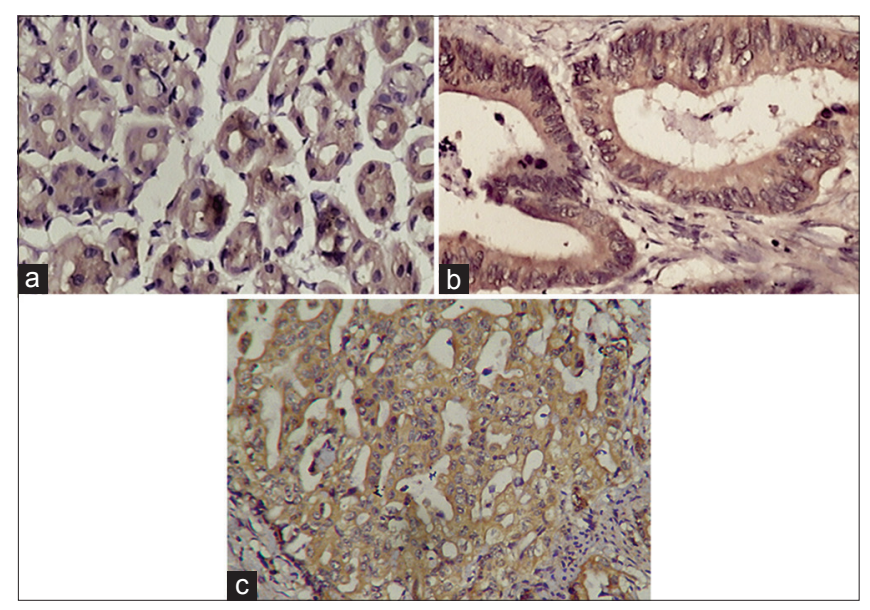

Figure 2: (a) Tau protein poorly positive expression in normal gastric mucosa (Immunohistochemisty $\times 200$ ). (b) Tau protein positive expression in Well-moderately differentiated gastric carcinoma (Immunohistochemisty $\times 200$ ). (c) Tau protein strongly positive expression in poorly differentiated gastric carcinoma (Immunohistochemisty $\times 200$ ) 
Such repetitive sequences are binding sites of microtubules in normal physiological conditions. In addition, some Tau protein isomeride amino terminus consists of the insert element, which contain 29 or 58 amino acid residues. Tau protein degrade their dynamic instability by combining with microtubules, improve the unification velocity of microtubule protein molecules in microtubule growth end, and decrease the velocity of microtubule protein separation, inhibit their transition to decurtation term. Tau protein has similar function in vivo, several laboratory have already transfected the Tau gene into normal cell which do not express Tau protein. ${ }^{5,6}$ In transfected cells, Tau protein enhance the stability of microtubules by combining with microtubules. ${ }^{7}$ Fasciation can make microtubules stability, and Tau protein may facilitate such function. ${ }^{8}$ The main biological function of Tau protein is as follows: Regulate and control the assembling of mirotubules. On the one hand, MAP can contribute the formation of microtubule protein polymerization core, accelerate the polymerization of microtubule protein, make microtubules grow and extend, by the mechanism that microtubules combining areas in peptide chain of MAP and several microtubules protein bind simultaneously. On the other hand, MAP can relieve the combining activity with microtubules, retardant the polymerization of microtubule protein, delay the assembling of microtubules, by the character that the overhanging function area of MAP can be phosphorylated by MAP-kinase. It can build, stabilize and strengthen cytoskeletal structure. Participate in the rail directional transhipment of intracellular material, Participate in and mediate the cellular signal transduction.

The researches on Tau protein and Tau mRNA most prone to the nervous system, but rarely refer to gastric carcinoma tissue. $^{9-11}$ From its biological function, we can find that the combination of Tau protein and microtubules can induce microtubules to bundle and enhance the stability of microtubules. As the essential component of spindle in mitotic period, microtubules make cell cycle proceed smoothly, provide conditions for infite appreciation of cancer cells. Just Tau protein assists such function which may accelerate the progress of malignant tumors.

This experiment have detected the expression of Tau protein and Tau mRNA in normal and carcinomatous gastric tissue. The research results indicate that the expression of Tau protein and Tau mRNA in normal gastric tissue is lower than those in carcinomatous gastric tissue and its relevance to the differentiation and lymph node metastasis of gastric carcinoma, that means the expression of Tau protein and Tau mRNA may increase in carcinomatous gastric tissue. Tau protein may participate in the occurrence and development of gastric carcinoma by affecting the signal transmission of carcinomatous gastric cells. Meanwhile, Tau protein can also be used as the target of the targeted therapy against gastric carcinoma.

\section{REFERENCES}

1. Vouyiouklis DA and Brophy PJ. Microtubule-associated proteins in developing oligodendrocytes: Transient expression of a MAP2c isoform in oligodendrocyte precursors. J Neurosci Res 1995;42(6):803-817.

2. Dehmelt $L$ and Halpain $S$. The MAP2/Tau family of microtubuleassociated proteins. Genome Biol 2005;6(1):204.

3. Iqbal K, Liu F, Gong CX and Grundke-lqbal I. Tau in Alzheimer disease and related tauopathies. Curr Alzheimer Res 2010;7(8):656-664.

4. Sun $Q$ and Gamblin TC. Pseudohyperphosphorylation causing AD-like changes in tau has significant effects on its polymerization. Biochemistry 2009;48(25):6002-6011.

5. Qureshi HY and Paudel HK. Parkinsonian neurotoxin 1-methyl-4phenyl-1,2,3,6-tetrahydropyridine (MPTP) and alpha-synuclein mutations promote Tau protein phosphorylation at Ser262 and destabilize microtubule cytoskeleton in vitro. J Biol Chem 2011; 286(7):5055-5068.

6. Lee S, Jung C, Lee G and Hall GF. Exonic point mutations of human tau enhance its toxicity and cause characteristic changes in neuronal morphology, tau distribution and tau phosphorylation in the lamprey cellular model of tauopathy. J Alzheimers Dis 2009;16(1):99-111.

7. Fauquant C, Redeker V, Landrieu I, Wieruszeski JM, Verdegem $D$, Laprévote $O$, et al. Systematic identification of tubulin-interacting fragments of the microtubule-associated protein Tau leads to a highly efficient promoter of microtubule assembly. J Biol Chem 2011;286(38):33358-33368.

8. Jung K, Goerdt C, Lange P, Blocher J, Djukic M, Gerber J, et al. The use of $\mathrm{S} 100 \mathrm{~B}$ and Tau protein concentrations in the cerebrospinal fluid for the differential diagnosis of bacterial meningitis: A retrospective analysis. Eur Neurol 2011;66(3):128-132.

9. Mimori K, Sadanaga N, Yoshikawa Y, Ishikawa K, Hashimoto M, Tanaka $\mathrm{F}$, et al. Reduced tau expression in gastric cancer can identify candidates for successful Paclitaxel treatment. $\mathrm{Br} J$ Cancer 2006;94(12):1894-1897.

10. Sakamoto J, Matsui T and Kodera Y. Paclitaxel chemotherapy for the treatment of gastric cancer. Gastric Cancer 2009;12(2):69-78.

11. Scartozzi M, Galizia E, Verdecchia L, Berardi R, Antognoli S, Chiorrini S, et al. Chemotherapy for advanced gastric cancer: Across the years for a standard of care. Expert Opin Pharmacother 2007;8(6):797-808.

\footnotetext{
Authors Contribution:

Chun-Hui Li - Contributed to the original idea, designed the study; Li-Hui Pan and Rajina Sahi - Conceived hypothesis, designed study, preparing of manuscript and reviewing the manuscript; Xing Zhao - Contributed to the study design, data analysis. Yu Cheng and Zhang De-Li - Contributed to patient enrolment, data analysis.

Source of Support: Hebei province key research subject of medical science and government funding plan , China, Hebei province (ZL20140103), Conflict of Interest: None declared.
} 